\title{
PENGARUH KUALITAS PELAYANAN DAN PERSEPSI NILAI TERHADAP KEPUASAN UNTUK MENINGKATKAN WORD OF MOUTH PARTY PLANNER
}

\author{
Alicia Alexandra ${ }^{1}$ \\ Ni Wayan Sri Suprapti \\ ${ }^{1,2}$ Fakultas Ekonomi dan Bisnis Universitas Udayana (Unud), Bali,Indonesia \\ e-mail : alicialexandra@gmail.com
}

\begin{abstract}
ABSTRAK
Penelitian ini bertujuan untuk mengetahui pengaruh kualitas pelayanan dan persepsi nilai terhadap kepuasan pelanggan untuk meningkatkan word of mouth bagi pengguna jasa party planner. Data diambil dengan menggunakan kuesioner dari 107 responden di Kota Denpasar yang sudah pernah menggunakan jasa tersebut minimal sekali dalam dua tahun terakhir. Data diolah menggunakan analisis regresi. Hasil penelitian menemukan bahwa kualitas pelayanan dan persepsi nilai berpengaruh positif dan signifikan terhadap kepuasan pelanggan. Selain itu kepuasan pelanggan juga berpengaruh positif dan signifikan terhadap word of mouth. Hasil ini menunjukkan bahwa untuk meningkatkan word of mouth yang positif, perusahaan diharapkan mampu mempertahankan atau meningkatkan kepuasan pelanggan. Kepuasan pelanggan dapat dipertahankan atau ditingkatkan dengan cara menjaga atau meningkatkan kualitas pelayanan dan persepsi nilai.
\end{abstract}

Kata kunci: kualitas layanan, persepsi nilai, kepuasan pelanggan, word of mouth

\begin{abstract}
This study aims to determine the effect of service quality and perceived value on customer satisfaction to improve word of mouth for party planner service users. Data was taken using a questionnaire from 107 respondents in Denpasar City who had used the service at least once in the last two years. Data is processed using regression analysis. The results of the study found that service quality and value perception had a positive and significant effect on customer satisfaction. In addition, customer satisfaction also has a positive and significant effect on word of mouth. These results indicate that to improve positive word of mouth, the company is expected to be able to maintain or increase customer satisfaction. Customer satisfaction can be maintained or improved by maintaining or improving service quality and perceived value.
\end{abstract}

Keywords: service quality, perceived value, customer satisfaction, word of mouth 


\section{PENDAHULUAN}

Semakin tinggi tingkat mobilitas seseorang yang tinggal di perkotaan, menjadikannya kekurangan waktu untuk mempersiapkan segala sesuatu yang menyangkut hari spesialnya seperti hari jadi dengan pasangan, ulang tahun anggota keluarga atau ulang tahun sahabat, syukuran dan perayaan-perayaan lainnya terutama yang bersifat private party seperti acara baby shower, bridal shower, candle light dinner, dan surprise party. Masyarakat kota yang ingin mewujudkan perayaan - perayaan spesial tersebut, tentu membutuhkan bantuan dari orang lain seperti sanak keluarga. Namun, dengan keterbatasan bantuan dari sanak keluarga maka diperlukanlah bantuan dari jasa party planner. Jasa ini menawarkan semua hal yang berkaitan dengan pelaksanaan pesta, mulai dari merancang konsep awal acara dengan calon pengguna, penataan dekorasi, pemilihan pembawa acara sampai acara hiburan saat pesta berlangsung. Semua itu dirancang dengan menggabungkan keinginan client dan imajinasi dari konseptor agar menghasilkan kepuasan bagi pemakai jasa party planner.

Sampai dengan tahun 2017, terdapat beberapa usaha di Kota Denpasar yang menyediakan jasa seperti ini, diantaranya Party Love Good, Make Yours Decorations, SLMF (She Loves Me Flower) dan L Decoration. Salah satu yang mulai berkembang adalah ORGANIZER.id. Usaha ini menawarkan berbagai jasa dekorasi seperti dekorasi ruangan, pesta ulang tahun, syukuran, makan malam romantic, dan lain sebagainya. Sejak didirikan awal 2015, jenis dan jumlah pelanggan yang dilayani disajikan pada Tabel 1. 
Tabel 1.

Data Pelanggan (Paket) ORGANIZER.id Tahun 2015 - 2017

\begin{tabular}{lccccccc}
\hline & $\begin{array}{c}\text { Room } \\
\text { Decoration }\end{array}$ & $\begin{array}{c}\text { Birthday } \\
\text { Party }\end{array}$ & $\begin{array}{c}\text { Bridal } \\
\text { Shower }\end{array}$ & $\begin{array}{c}\text { Baby } \\
\text { Shower }\end{array}$ & $\begin{array}{c}\text { Romantic } \\
\text { Dinner }\end{array}$ & Lainnya & Jumlah \\
\hline $\mathbf{2 0 1 5}$ & 5 & 10 & 1 & 0 & 4 & 4 & 24 \\
$\mathbf{2 0 1 6}$ & 29 & 48 & 14 & 2 & 19 & 7 & 119 \\
$\mathbf{2 0 1 7}$ & 23 & 33 & 11 & 1 & 11 & 14 & 93 \\
\hline
\end{tabular}

Data pada Tabel 1, menunjukkan kenaikan jumlah pelanggan di tahun 2016 dan penurunan di tahun berikutnya. Terjadinya penurunan dapat disebabkan oleh berbagai faktor seperti munculnya party planner pesaing dari segi harga di Kota Denpasar dan sekitarnya seperti Party Love Good dan Make Yours Decorations. Selain itu, pesaing dengan kualitas yang mumpuni seperti SLMF (She Loves Me Flower) dan L Decoration. Banyaknya pilihan jasa party planner yang ada akan berdampak pada kecenderungan pelanggan tidak lagi menggunakan jasa pelayanan yang ditawarkan oleh ORGANIZER.id karena ingin mengetahui bagaimana pelayanan dari jasa party planner lainnya dan harga yang lebih murah. Selain itu, kini sudah banyak cafe dan hotel yang menyediakan pelayanan dekorasi sendiri bagi pengujung yang membutuhkan dan sudah membuatnya dalam pilihan paket. Harga paket yang ditawarkan oleh cafe dan hotel biasanya sudah termasuk dengan makanan dan minuman dari mereka sendiri atau pun kamar hotel. Seperti halnya paket makan malam romantis atau paket bulan madu. 
Tabel 2.

Daftar Harga (Paket) Pelayanan dan Fasilitas ORGANIZER.id Tahun 2015 - 2017

\begin{tabular}{|c|c|c|c|c|}
\hline Jenis Pelayanan & & $\begin{array}{l}\text { Harga } \\
\text { mulai dari) }\end{array}$ & Fasilitas & Ket. \\
\hline Room Decoration & $\mathrm{Rp}$ & 650,000 & $\begin{array}{l}\text { Hellium baloons, flower petals, } \\
\text { bunting flag, bouquet flower }\end{array}$ & by request \\
\hline \multirow[t]{2}{*}{ Table Setting } & $\mathrm{Rp}$ & 100,000 & $\begin{array}{l}\text { Flower Arrangement, table runner } \\
\text { (placemate), chair sash, candle, photo } \\
\text { frame or quote, baloons, cake stand }\end{array}$ & $\begin{array}{l}\text { Harga per } \\
\text { pax, } \\
\text { min. } 8 \text { pax }\end{array}$ \\
\hline & $\mathrm{Rp}$ & 150,000 & & $\begin{array}{l}\text { Harga per } \\
\text { pax, } \\
\text { min. } 4 \text { pax }\end{array}$ \\
\hline Sweetcorner & \multicolumn{2}{|c|}{$\operatorname{Rp} 2,500,000$} & $\begin{array}{l}\text { Table Corner Decoration (baloon, } \\
\text { table cloth, photo frame, decoration } \\
\text { based on theme, flower arrangement, } \\
\text { candle, welcome sign, } \\
\text { gate balon), Backdrop } 2.5 \text { m x } 2.5 \mathrm{~m} \text {, } \\
\text { Snack (Cake pop 10pcs, Chocolate } \\
\text { ball 10pcs, Marsmalow 10pcs, } \\
\text { Cupcake 10pcs, Milk bottle 10pcs) }\end{array}$ & by request \\
\hline \multirow[t]{2}{*}{ Photobooth } & \multicolumn{2}{|c|}{ Rp 1,000,000 } & $\begin{array}{l}\text { Printing backdrop } 2 \times 3 \text { with fairy } \\
\text { light, decoration stuff setup based by } \\
\text { theme, ballons } 30 p c s\end{array}$ & by request \\
\hline & \multicolumn{2}{|c|}{$\operatorname{Rp} 2,500,000$} & $\begin{array}{l}\text { Backdrop decoration and decoration } \\
\text { pieces by based by theme,photoboth } \\
\text { props }\end{array}$ & $2 \times 3 \mathrm{~m}$ area \\
\hline Romantic Dinner & $\mathrm{Rp}$ & 500,000 & $\begin{array}{l}\text { Flower Arrangement, table runner } \\
\text { (placemate), chair sash, candle, photo } \\
\text { frame or quote, baloons }\end{array}$ & by request \\
\hline \multirow[t]{4}{*}{ Additional } & $\mathrm{Rp}$ & 200,000 & Standar Cake & by request \\
\hline & $\mathrm{Rp}$ & 400,000 & Cake 2 tier & \\
\hline & $\mathrm{Rp}$ & $1,000,000$ & Photographer & \\
\hline & $\mathrm{Rp}$ & 100,000 & Additional Pack & \\
\hline
\end{tabular}

Sumber : Data Internal ORGANIZER.id

Jasa party planner ialah salah satu bagian dari industri jasa, dimana jasa bukanlah sesuatu yang berwujud, maka pelaku jasa perlu menunjukkan kualitas pelayanannya. Seperti yang diungkapkan Harjati dan Yurike (2015) bahwa, kualitas pelayanan dapat diketahui dengan cara membandingkan persepsi para pelanggan atas pelayanan yang secara nyata mereka terima atau peroleh dengan 
pelayanan yang sesungguhnya mereka harapkan atau inginkan terhadap atributatribut pelayanan suatu perusahaan. Selain kualitas pelayanan, terdapat pula persepsi nilai yang mempengaruhi kepuasan pelanggan. Peter dan Jerry (2000:228) dalam bukunya Consumer Behavior telah menyatakan bahwa, persepsi nilai berkaitan dengan bagaimana informasi harga dipahami seluruhnya oleh konsumen dan memberikan makna yang dalam bagi mereka. Hasil penelitian Lai et al. (2016) juga menemukah bahwa kualitas pelayanan dan perpsepsi nilai memiliki efek langsung pada kepuasan. Pada Tabel 2 yaitu daftar harga pelayanan dan fasilitas yang disediakan oleh ORGANIZER.id disetiap jenis pelayanan. Seluruh harga yang ditawarkan oleh ORGANIZER.id sudah sangat dipertimbangkan dan dianggap wajar oleh para client nya karena sesuai dengan fasilitas dan pelayanan yang didapatkan.

Penelitian sebelumnya yang dilakukan oleh Sinaga (2011) menemukan bahwa, kualitas pelayanan merupakan salah satu variabel untuk mencapai kepuasan pelanggan karena pelanggan yang puas akan memberikan dampak kepada word of mouth sehingga akan memberikan nilai kepada perusahaan. Hal ini juga didukung oleh penelitian yang dilakukan oleh Widyaswati (2010) ditemukan bahwa semakin tinggi kepuasan pelanggan maka semakin tinggi word of mouth positif dapat diterima. Namun berbeda dengan hasil penelitian yang dilakukan oleh Shao (2013), ia menemukan bahwa tidak ada hubungan yang signifikan antara kepuasan dengan perilaku word of mouth. Penelitian ini dilakukan untuk mengetahui kelanjutan dari kepuasan pelanggan setelah mendapatkan pelayanan dari jasa party planner tersebut dan sudah kah berdampak 
kepada pelaku jasa terutama jasa party planner karena bisnis ini berpeluang besar untuk meningkatkan word of mouth melalui kualitas pelayanan dan persepsi nilai yang dipengaruhi kepuasan konsumen.

Berdasarkan latar belakang, penelitian ini bertujuan untuk menjelaskan pengaruh kualitas pelayanan dan persepsi nilai terhadap kepuasan pelanggan dan untuk menjelaskan pengaruh kepuasan pelanggan terhadap word of mouth pengguna jasa party planner. Penelitian ini diharapkan nantinya dapat berguna bagi semua pihak yang membutuhkan baik secara teoritis maupun secara praktis Secara teoritis penelitian ini diharapkan dapat menambah pengetahuan, wawasan serta informasi dan dapat dijadikan sebagai referensi pada penelitian selanjutnya tentang strategi pemasaran jasa terutama jasa party planner yang berupa perilaku word of mouth. Secara praktis, penelitian ini diharapkan dapat menjadi pedoman bagi pemilik usaha jasa party planner dalam merumuskan strategi pemasaran yang akan datang sehingga mampu menimbulkan word of mouth baik melalui kepuasan pelanggan terhadap jasa yang mereka tawarkan dengan tetap menjaga kualitas pelayanan dan mempertimbangkan persepsi nilai dari sudut pandang pelanggan.

Definisi jasa menurut Kotler dan Keller (2012:214), sebagai setiap tindakan atau perbuatan yang dapat ditawarkan oleh suatu pihak kepada pihak lain yang pada dasarnya bersifat intangible (tidak berwujud fisik) dan tidak menghasilkan kepemilikan sesuatu. Salah satu pendukung jasa adalah kualitas pelayanan yang sangat bergantung pada tiga hal, yaitu sistem, teknologi dan manusia. Faktor manusia memberikan kontribusi sekitar 70\%. Oleh sebab itu, tidak mengherankan 
bila kepuasan terhadap kualitas pelayanan biasanya sulit ditiru. Lewis dan Booms (1983) dalam Tjiptono dan Chandra (2011:180) mendefinisikan kualitas pelayanan sebagai ukuran seberapa bagus tingkat pelayanan yang diberikan mampu sesuai dengan ekspektasi pelanggan. Kualitas pelayanan dapat diwujudkan melalui pemenuhan kebutuhan dan keinginan pelanggan serta ketepatan penyampaiannya untuk mengimbangi harapan pelanggan. Menurut Moenir dalam Tangkilisan (2005: 208), agar pelayanan dapat memuaskan orang atau kelompok orang yang dilayani, maka pelaku yang bertugas melayani harus memenuhi empat kriteria pokok yaitu sebagai berikut : 1) tingkah laku yang sopan, 2) cara menyampaikan sesuatu yang berkaitan dengan apa yang seharusnya diterima oleh orang yang bersangkutan, 3) waktu menyampaikan yang tepat, dan 4) keramahtamahan.

Pada dasarnya, persepsi nilai merupakan kecenderungan konsumen untuk menggunakan harga dalam memberi penilaian tentang kesesuaian manfaat produk. Penilaian terhadap harga pada suatu manfaat produk atau pelayanan dikatakan mahal, murah atau sedang dari masing- masing individu tidaklah sama, karena tergantung dari persepsi individu yang dilatar belakangi oleh lingkungan dan kondisi individu itu sendiri. Persepsi nilai juga didefinisikan sebagai semua nilai yang dirasakan oleh konsumen dengan pengalaman interaktif, relativistik dan preferensi, pengalaman ini dihasilkan dari apa yang mereka konsumsi (Holbrook, 1999 dalam Kuo, 2012). Persepsi konsumen terhadap suatu harga dapat mempengaruhi keputusan dalam membeli suatu produk sehingga suatu perusahaan harus mampu memberikan persepsi yang baik terhadap produk atau 
jasa yang mereka jual. Menurut Manu dan Dharmmesa (2016), persepsi nilai pelanggan dan persepsi nilai program memiliki pengaruh terhadap kepuasan pelanggan. Pelanggan berharap untuk "mendapatkan nilai dari uang mereka" (Lovelock, 2001). Semakin besar kesenjangan antara manfaat yang dirasakan dengan biaya yang dirasakan, semakin tinggi nilai yang dirasakan.

Arti kepuasan menurut Kamus Besar Bahasa Indonesia (KBBI) online adalah perihal (yang bersifat) puas; kesenangan; kelegaan dan sebagainya $\sim$ kerja, keadaan psikis yang menyenangkan yang dirasakan oleh pekerja dalam suatu lingkungan pekerjaan karena terpenuhinya semua kebutuhan secara memadai. Menurut Tjiptono dan Chandra (2011:292) "Kepuasan diartikan sebagai upaya pemenuhan sesuatu atau membuat sesuatu memadai". Oxford Advanced Learner's Dictionary dalam Tjiptono dan Chandra (2011:292) mendeskripsikan kepuasan sebagai: "The good feeling that you have when you achieved something or when something that you wanted to happen does happen" and "the act of fulfilling a need or desire", yang diartikan bahwa kepuasan adalah perasaan menyenangkan yang dimiliki saat mendapatkan sesuatu atau ketika sesuatu yang diinginkan terjadi dan aksi terpenuhinya kebutuhan dan keinginan.

Menurut Cardozo, Westbrook, Ostrom \& Iacobucci dalam Chang et al. (2016), kepuasan pelanggan adalah peninjauan keseluruhan pelanggan terhadap harga produk, efisiensi sistem operasi dan pelayanan internal perusahaan, sikap staf terhadap pelayanan pelanggan, staf profesional pengetahuan dan keterampilan, kinerja keseluruhan perusahaan, dan kedekatan perusahaan diimajinasi pelanggan. Umar (2003:14) juga menemukan bahwa kepuasan 
pelanggan adalah sebagai evaluasi purna beli, dimana persepsi terhadap kinerja alternatif produk atau pelayanan yang dipilih memenuhi atau melebihi harapan sebelum pembelian. Apabila persepsi terhadap kinerja tidak dapat memenuhi harapan, maka yang terjadi adalah ketidakpuasan. Ditemukan dalam penelitian Moragan et al. (2008), bahwa kepuasan tercipta pada saat perusahaan dapat memenuhi kebutuhan konsumen dengan baik. Dari beberapa teori yang telah dikemukakan sebelumnya, disimpulkan bahwa kepuasan pelanggan dapat diukur dengan menanyakan langsung kepada pelanggan, seberapa puas mereka oleh produk dan jasa tertentu dengan indikator antara lain loyal terhadap produk, menjadikan jasa tersebut sebagai pertimbangan utama dalam membeli jasa yang sejenis (niat beli ulang) dan merekomendasikan kepada orang-orang (word of mouth).

Word of mouth yang biasa disingkat WOM, dikenal juga sebagai komunikasi dari mulut ke mulut. Brown et al. (2005) dalam Harsasi (2006) mendefinisikan WOM sebagai informasi tentang suatu target objek yang dipindahkan dari satu individu ke individu lain yang dilakukan secara langsung atau tidak langsung melalui media komunikasi. Jika WOM dimanfaatkan dengan benar, bisa memasarkan produk atau jasa apapun untuk waktu yang lama (Ahmad et al., 2014:394).

WOM sangat efektif diterapkan di Indonesia terutama di kota besar seperti Denpasar, Bali. Hal ini dikarenakan orang (konsumen) Indonesia yang memiliki karakter unik, yaitu berkumpul dan bersosialisasi secara informal seperti yang disebutkan dalam majalah marketing online edisi khusus "10 Karakter Unik 
Konsumen Indonesia”. Lovelock (2001) dalam Praswati (2009) juga mengemukakan bahwa pendapat yang diberikan konsumen tentang pengalaman jasa memiliki pengaruh yang lebih kuat dibanding iklan atau tenaga penjual terhadap keputusan pembelian. Karena pada dasarnya, word of mouth lebih dipercaya dibandingkan oleh seorang sales person, dan dapat menjangkau konsumen lebih cepat daripada iklan maupun direct mail, karena kekuatan word of mouth terletak pada kemampuannya dalam memberikan rekomendasi (referral) menurut Muhammad (2010).

Hal ini sejalan dengan apa yang dinyatakan Dye (2000) bahwa dalam kehidupan sehari-hari orang senang sekali untuk membagi pengalamannya tentang sesuatu. Misalnya, membicarakan restoran, produk yang dibeli, jasa yang digunakan atau film yang ditonton kemudian merekomendasikannya kepada orang lain. Apabila kinerja sesuai atau bahkan melebihi harapan, maka konsumen akan merasa senang atau puas. Sebaliknya apabila kinerja berada di bawah harapan, maka konsumen akan merasa kecewa atau tidak puas (Prabowo dan Suryono, 2016).

Penelitian yang dilakukan Ngadino et al. (2017), Susie et al. (2017), Firdous dan Rahela (2017), Silvestri et al. (2017), Nuseir et al. (2010), Khan et al. (2012), Putra dan Eka (2017) menemukan bahwa kualitas pelayanan berpengaruh positif dan signifikan terhadap kepuasan pelanggan. Berdasarkan hasil-hasil penelitian tersebut, maka dapat diajukan hipotesis sebagai berikut :

$\mathrm{H}_{1}$ : Kualitas pelayanan berpengaruh positif terhadap kepuasan pelanggan 
Penelitian yang dilakukan Su (2012) dalam Chang et al. (2016), Kertajaya (2002), Putra dkk. (2017), Raharjo dan Amboningtyas (2017), Wu (2014), Hapsari et al. (2016) menunjukkan bahwa persepsi nilai berpengaruh positif dan signifikan terhadap kepuasan pelanggan. Berdasarkan hasil-hasil penelitian tersebut, maka dapat diajukan hipotesis sebagai berikut :

$\mathrm{H}_{2}$ : Persepsi nilau berpengaruh positif terhadap kepuasan pelanggan

Penelitian yang dilakukan Mulyana (2002), Priharmoko (2003), Kurniawan (2016), Saputra dan Suryono (2011), Yucekaya et al. (2017), Prabowo dan Suryono (2016) menemukan bahwa kepuasan pelanggan berpengaruh positif dan signifikan terhadap word of mouth. Berdasarkan hasil-hasil penelitian tersebut, maka dapat diajukan hipotesis sebagai berikut :

$\mathrm{H}_{3}$ : Kepuasan pelanggan berpengaruh positif terhadap word of mouth

Berdasarkan kajian pustaka dan hasil studi empiris sebelumnya, maka kerangka konseptual disusun sebagai berikut,

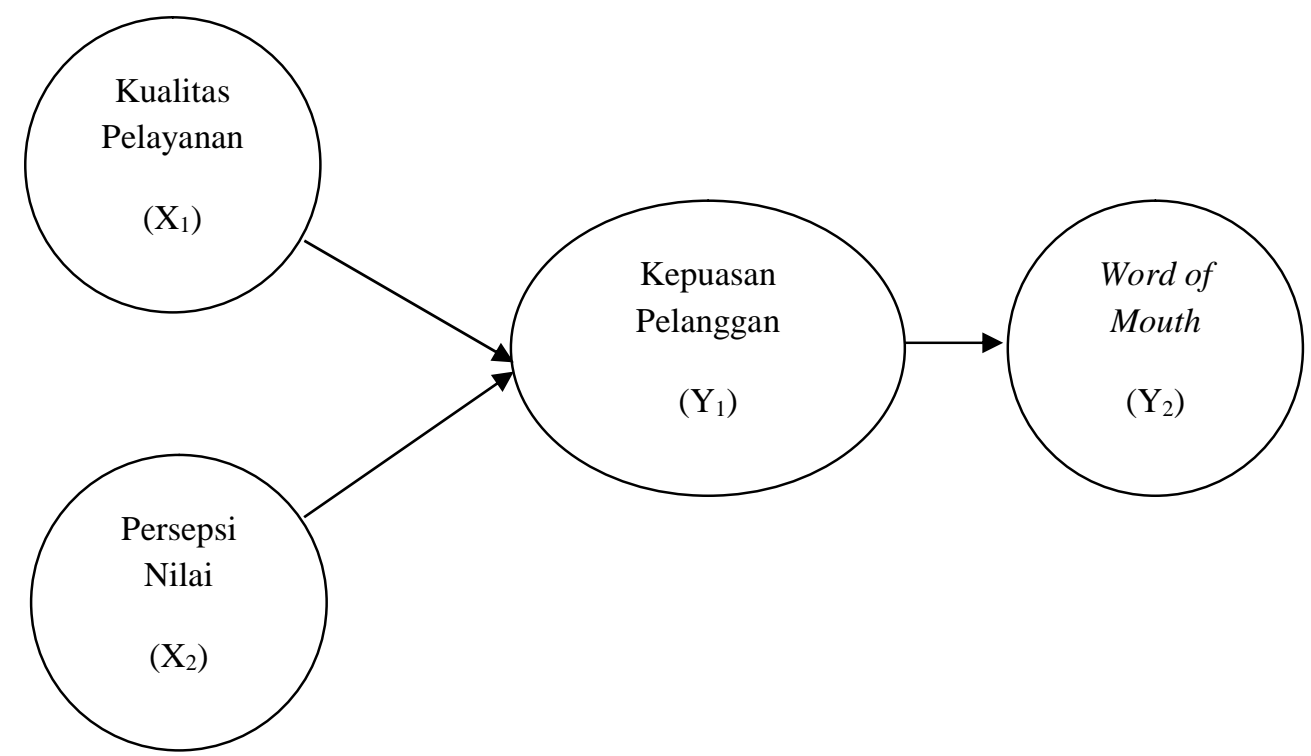

Gambar 1. Kerangka Konseptual 


\section{METODE PENELITIAN}

Penelitian ini bersifat asosiatif karena bertujuan untuk mengetahui hubungan antar variabel. Variabel penelitan terdiri dua variabel bebas yaitu variabel kualitas pelayanan $\left(\mathrm{X}_{1}\right)$ dan persepsi nilai $\left(\mathrm{X}_{2}\right)$, satu variabel mediator yaitu kepuasan pelanggan $\left(\mathrm{Y}_{1}\right)$ dan satu variabel terikat yaitu word of mouth $\left(\mathrm{Y}_{2}\right)$. Kempat variabel tersebut diukur menggunakan 13 indikator yang disajikan secara ringkas dalam Tabel 3.

Tabel 3.

Indikator Penelitian

\begin{tabular}{|c|c|c|c|c|}
\hline \multicolumn{2}{|c|}{ Variabel Penelitian } & \multicolumn{2}{|r|}{ Indikator } & \multirow{2}{*}{$\begin{array}{c}\text { Referensi } \\
\text { Moenir dalam } \\
\text { Tangkilisan } \\
(2005: 208)\end{array}$} \\
\hline Independen & $\begin{array}{l}\text { Kualitas } \\
\text { Pelayanan } \\
\quad \text { (X1) }\end{array}$ & $\begin{array}{l}\text { 1) } \\
\text { 2) } \\
\text { 3) } \\
\text { 4) }\end{array}$ & $\begin{array}{l}\text { Tingkah laku yang sopan } \\
\text { Komunikasi yang baik } \\
\text { Tepat waktu } \\
\text { Keramahtamahan }\end{array}$ & \\
\hline & $\begin{array}{l}\text { Persepsi Nilai } \\
\left(\mathrm{X}_{2}\right)\end{array}$ & $\begin{array}{l}\text { 2) } \\
\text { 3) }\end{array}$ & $\begin{array}{l}\text { Kesesuaian harga dengan } \\
\text { kualitas pelayanan } \\
\text { Daya saing harga } \\
\text { Kesesuaian harga dengan } \\
\text { manfaat yang didapatkan }\end{array}$ & $\begin{array}{l}\text { Kotler dan } \\
\text { Armstong } \\
(2012: 52)\end{array}$ \\
\hline \multirow[t]{2}{*}{ Dependen } & $\begin{array}{l}\text { Kepuasan } \\
\text { Pelanggan } \\
\quad\left(\mathrm{Y}_{1}\right)\end{array}$ & $\begin{array}{l}\text { 2) } \\
\text { 3) }\end{array}$ & $\begin{array}{l}\text { Perasaan puas atau senang } \\
\text { terhadap pelayanan yang } \\
\text { diberikan } \\
\text { Harapan yang terpenuhi } \\
\text { Puas secara keseluruhan }\end{array}$ & $\begin{array}{c}\text { Umar } \\
(2003: 14,15)\end{array}$ \\
\hline & $\begin{array}{l}\text { Word of Mouth } \\
\qquad\left(\mathrm{Y}_{2}\right)\end{array}$ & $\begin{array}{l}\text { 1) } \\
\text { 2) }\end{array}$ & $\begin{array}{l}\text { Menceritakan hal positif } \\
\text { Merekomendasikan kepada } \\
\text { orang lain } \\
\text { Mendorong teman atau relasi } \\
\text { untuk menggunakan }\end{array}$ & $\begin{array}{c}\text { Widyaswati } \\
(2010)\end{array}$ \\
\hline
\end{tabular}

Populasi dalam penelitian ini adalah seluruh pelanggan yang pernah menggunakan jasa party planner ORGANIZER.id. Metode penentuan sampel yang digunakan adalah non probability sampling dengan teknik purposive sampling yaitu teknik penentuan sampel dengan pertimbangan tertentu. Terdapat 13 indikator yang digunakan sehingga minimal banyaknya responden yang 
diambil sebagai sampel adalah 5 x $13=65$ responden dan maksimal responden yang diambil sebagai sampel adalah $10 \times 13=130$ responden. Sampel yang digunakan oleh peneliti sebanyak 107 responden dikarenakan saat proses penyebaran kuisioner sejumlah maksimum yaitu 130 responden hanya kembali 110 responden dan tersortir lagi sesuai kriteria responden, antara lain: sudah pernah menggunakan jasa party planner ORGANIZER.id di Denpasar minimal satu kali dalam dua (2) tahun terakhir dan berpendidikan.

Data dari responden dikumpulkan menggunakan metode survei dengan cara menyebarkan kuisioner. Kuesioner disebarkan secara langsung oleh peneliti dengan harapan hasil yang didapatkan sesuai realita. Dengan jenis data yang digunakan adalah data kualitatif berupa gambaran umum mengenai jasa party planner di Denpasar dan pendapat responden dalam kuisioner, serta data kuantitatif berupa usia, frekuensi penggunaan, pendapatan, data jumlah pelanggan ORGANIZER.id Tahun 2015-2017, dan daftar harga pelayanan dan fasilitas ORGANIZER.id Tahun 2015-2017. Sumber data dalam penelitian ini terdiri dari sumber primer yang diperoleh langsung dari responden dengan cara pengumpulan data menggunakan kuisioner dan sumber sekunder dari studi pustaka melalui berbagai jurnal, penelitian terdahulu, maupun artikel yang diambil dari internet, dan informasi dari internal ORGANIZER.id.

Instrumen penelitian ini berupa kuesioner yang terdiri atas sejumlah pertanyaan, terdiri dari pertanyaan terbuka dan tertutup. Pernyataan terbuka meliputi nama responden, usia responden, jenis kelamin dan pekerjaan responden. Pernyataan tertutup merupakan pernyataan yang telah dan diberikan pilihan 
jawabannya dalam jumlah yang terbatas. Butir-butir pernyataan dalam kuesioner diukur dengan Skala Likert. Instrumen penelitian terlebih dahulu diuji untuk mengetahui validitas dan reliabilitasnya.

Data-data yang diperoleh dianalisis menggunakan statistik deskriptif dan statistik inferensial. Statistik deskriptif berupa rata-rata usia responden dan ratarata skor jawaban dari kuesioner. Rata-rata skor jawaban responden terhadap indikator-indikator variabel dikelompokkan ke dalam 5 kelas interval dengan rentang penilaian seperti dalam Tabel 4.

Tabel 4.

\begin{tabular}{ccc}
\multicolumn{3}{c}{ Rentang Penelitian Jawaban Responden } \\
\hline No & Rentang & Kriteria \\
\hline 1 & $1,00-1,79$ & Sangat Tidak Baik \\
2 & $1,80-2,59$ & Tidak Baik \\
3 & $2,60-3,39$ & Cukup Baik \\
4 & $3,40-4,19$ & Baik \\
5 & $4,20-5,00$ & Sangat Baik \\
\hline \multicolumn{2}{l}{ Sumber: Wirawan, 2002}
\end{tabular}

Untuk menguji hipotesis penelitian, digunakan statistik inferensial berupa analisis reresi berganda.

\section{HASIL DAN PEMBAHASAN}

Data dikumpulkan dari 107 responden di Kota Denpasar dengan profil demografis disajikan pada Tabel 5. 
Tabel 5.

Profil Responden

\begin{tabular}{|c|c|c|c|c|}
\hline No. & Variabel & Klasifikasi & $\begin{array}{c}\text { Jumlah } \\
\text { (Orang) }\end{array}$ & $\begin{array}{c}\text { Persentase } \\
(\%)\end{array}$ \\
\hline 1. & $\begin{array}{l}\text { Jenis } \\
\text { Kelamin }\end{array}$ & $\begin{array}{l}\text { Laki-laki } \\
\text { Perempuan } \\
\text { Jumlah }\end{array}$ & $\begin{array}{c}23 \\
84 \\
\mathbf{1 0 7}\end{array}$ & $\begin{array}{l}21,5 \\
78,5 \\
\mathbf{1 0 0}\end{array}$ \\
\hline 2. & Usia (tahun) & $\begin{array}{l}17-22 \\
23-28 \\
29-34 \\
>=35 \\
\text { Jumlah }\end{array}$ & $\begin{array}{c}88 \\
14 \\
4 \\
1 \\
107\end{array}$ & $\begin{array}{c}82 \\
13 \\
4 \\
1 \\
100\end{array}$ \\
\hline 3. & $\begin{array}{l}\text { Jenjang } \\
\text { Pendidikan }\end{array}$ & $\begin{array}{l}\text { SMP } \\
\text { SMA } \\
\text { Perguruan Tinggi } \\
\text { Jumlah }\end{array}$ & $\begin{array}{c}16 \\
78 \\
13 \\
\mathbf{1 0 7}\end{array}$ & $\begin{array}{c}15 \\
73 \\
12 \\
\mathbf{1 0 0}\end{array}$ \\
\hline 4. & Pekerjaan & $\begin{array}{l}\text { Pegawai Swasta } \\
\text { Pelajar } \\
\text { Lainnya } \\
\text { Jumlah }\end{array}$ & $\begin{array}{c}14 \\
80 \\
13 \\
\mathbf{1 0 7}\end{array}$ & $\begin{array}{c}13 \\
75 \\
12 \\
\mathbf{1 0 0}\end{array}$ \\
\hline
\end{tabular}

Data menunjukkan bahwa para pengguna jasa party planner

ORGANIZER.id didominasi oleh perempuan. Hal ini menjadi wajar karena perempuan cenderung lebih suka mengadakan pesta untuk memperingati hari-hari spesialnya dibandingkan laki-laki. Dilihat dari usianya, mereka berada pada usia remaja, yaitu yang masih duduk di bangku SMA (tamat SMP) dan yang sedang kuliah pada jenjang Sarjana (tamat SMA).

Sebelum digunakan mengumpulkan data, kuesioner terlebih dahulu diuji vaiditas dan reliabilitasnya. Hasil pengujian disajikan pada Tabel 6. Seluruh indikator telah dinyatakan valid (tepat) dan reliabel (konsisten) karena sudah memenuhi masing-masing syarat pengujian. Seluruh indikator memiliki koefisien korelasi > 0,3 dan koefisien reliabilitas (Cronbach's Alpha) > 0,6. 
Tabel 6.

Hasil Uji Validitas dan Reliabilitas

\begin{tabular}{cccccc}
\hline Variabel & Instrumen & $\begin{array}{c}\text { Koefisien } \\
\text { Korelasi }\end{array}$ & Ket. & $\begin{array}{c}\text { Cronbach's } \\
\text { Alpha }\end{array}$ & Ket. \\
\hline Kualitas Pelayanan & X 1.1 & 0,877 & Valid & & \\
(X1) & X 1.2 & 0,928 & Valid & 0,922 & Reliabel \\
& X 1.3 & 0,911 & Valid & & \\
X 1.4 & 0,890 & Valid & & \\
Persepsi Nilai & X 2.1 & 0,853 & Valid & & Reliabel \\
$\left(\mathrm{X}_{2}\right)$ & X 2.2 & 0,852 & Valid & 0,813 & \\
& X 2.3 & 0,856 & Valid & & Reliabel \\
Kepuasan Pelanggan & Y 1.1 & 0,907 & Valid & & \\
$\left(Y_{1}\right)$ & Y 1.2 & 0,943 & Valid & 0,914 & Reliabel \\
Word of Mouth & Y 1.3 & 0,924 & Valid & & \\
(Y) & Y 2.1 & 0,909 & Valid & & \\
& Y 2.2 & 0,925 & Valid & 0,909 & \\
& Y 2.3 & 0,926 & Valid & & \\
\hline
\end{tabular}

Sumber: Data diolah, 2018

Data tentang tanggapan atau pendapat responden terhadap setiap butir pernyataan dalam kuisioner, hasilnya disajikan pada Tabel 7. Ditunjukan bahwa variabel kualitas layanan memiliki rata-rata skor adalah sebesar 4,18 berkategori baik yang artinya responden memiliki persepsi yang baik akan kualitas pelayanan yang diberikan ORGANIZER.id. Variabel persepsi nilai memiliki rata-rata skor sebesar 3,87 berkategori baik, artinya responden memiliki persepsi baik tentang harga yang ditawarkan ORGANIZER.id dan nilai yang didapatkan para konsumen. Variabel kepuasan pelanggan memiliki rata-rata sebesar 4,14 berkategori baik, artianya responden terpuaskan oleh pelayanan ORGANIZER.id. Variabel word of mouth memiliki rata-rata skor sebesar 4,11 berkategori baik, artinya responden bersedia merekomendasikan jasa party planner ORGANIZER.id kepada orang-orang di sekitarnya. 
Tabel 7.

Penilaian Responden Terhadap Masing-Masing Variabel

\begin{tabular}{|c|c|c|c|c|c|c|c|c|}
\hline \multirow[t]{2}{*}{ No. } & \multirow[t]{2}{*}{ Pernyataan } & \multicolumn{5}{|c|}{$\begin{array}{c}\text { Proporsi Jawaban } \\
\text { Responden }(\%) \\
\end{array}$} & \multirow{2}{*}{$\begin{array}{l}\text { Rata- } \\
\text { rata }\end{array}$} & \multirow[t]{2}{*}{ Ket. } \\
\hline & & 1 & 2 & 3 & 4 & 5 & & \\
\hline 1. & $\begin{array}{l}\text { ORGANIZER.id memiliki karyawan } \\
\text { (tim) yang sopan dan santun. }\end{array}$ & 3 & 1 & 8 & 61 & 34 & 4,14 & Baik \\
\hline 2. & $\begin{array}{l}\text { ORGANIZER.id memiliki karyawan } \\
\text { (tim) yang mampu berkomunikasi } \\
\text { dengan baik. }\end{array}$ & 3 & 0 & 8 & 59 & 37 & 4,19 & Baik \\
\hline 3. & $\begin{array}{l}\text { ORGANIZER.id memberikan jasa } \\
\text { pelayanan yang tepat waktu sesuai } \\
\text { yang dijanjikan. }\end{array}$ & 2 & 1 & 8 & 61 & 35 & 4,18 & Baik \\
\hline 4. & $\begin{array}{l}\text { Karyawan (tim) ORGANIZER.id } \\
\text { berkemampuan baik dalam menangkap } \\
\text { konsep pesta yang diinginkan dan } \\
\text { memberikan solusi untuk mengatasi } \\
\text { masalah konsumen. }\end{array}$ & 3 & 1 & 8 & 53 & 42 & 4,21 & $\begin{array}{l}\text { Sangat } \\
\text { Baik }\end{array}$ \\
\hline
\end{tabular}

\begin{tabular}{|c|c|c|c|c|c|c|c|c|}
\hline \multicolumn{7}{|c|}{ Rata - Rata Keseluruhan } & \multirow{2}{*}{\begin{tabular}{|l|}
$\mathbf{4 , 1 8}$ \\
3,67
\end{tabular}} & \multirow{2}{*}{$\begin{array}{l}\text { Baik } \\
\text { Baik }\end{array}$} \\
\hline 1. & $\begin{array}{l}\text { Harga yang ditawarkan } \\
\text { ORGANIZER.id sesuai dengan } \\
\text { kualitas pelayanan yang diberikan. }\end{array}$ & 1 & 5 & 39 & 45 & 17 & & \\
\hline 2. & $\begin{array}{l}\text { Harga yang ditawarkan } \\
\text { ORGANIZER.id sangat kompetitif } \\
\text { dibanding dengan jasa party planner } \\
\text { sejenis. }\end{array}$ & 2 & 1 & 18 & 62 & 24 & 3,98 & Baik \\
\hline 3. & $\begin{array}{l}\text { Harga yang dibayar sesuai dengan } \\
\text { manfaat yang didapatkan oleh } \\
\text { pengguna jasa party planner. }\end{array}$ & 1 & 0 & 27 & 53 & 26 & 3,96 & Baik \\
\hline
\end{tabular}

\begin{tabular}{|c|c|c|c|c|c|c|c|c|}
\hline \multicolumn{7}{|c|}{ Rata - Rata Keseluruhan } & \multirow{2}{*}{$\begin{array}{l}\mathbf{3 , 8 7} \\
4,15\end{array}$} & \multirow{2}{*}{$\begin{array}{l}\text { Baik } \\
\text { Baik }\end{array}$} \\
\hline 1. & $\begin{array}{l}\text { Saya merasa senang terhadap } \\
\text { pelayanan yang diberikan } \\
\text { ORGANIZER.id kepada penggunanya. }\end{array}$ & 1 & 1 & 9 & 66 & 30 & & \\
\hline 2. & $\begin{array}{l}\text { Harapan saya terpenuhi dengan } \\
\text { pelayanan yang diberikan } \\
\text { ORGANIZER.id. }\end{array}$ & 2 & 0 & 12 & 60 & 33 & 4,14 & Baik \\
\hline 3. & $\begin{array}{l}\text { Secara keseluruhan saya puas terhadap } \\
\text { pelayanan yang diberikan } \\
\text { ORGANIZER.id. }\end{array}$ & 1 & 3 & 10 & 60 & 33 & 4,14 & Baik \\
\hline \multicolumn{7}{|c|}{ Rata - Rata Keseluruhan } & 4,14 & Baik \\
\hline 1. & $\begin{array}{l}\text { Saya sukarela menceritakan hal positif } \\
\text { tentang ORGANIZER.id kepada orang } \\
\text { sekitar, seperti teman dan saudara. }\end{array}$ & 1 & 3 & 12 & 54 & 37 & 4,15 & Baik \\
\hline 2. & $\begin{array}{l}\text { Saya merekomendasikan } \\
\text { ORGANIZER,id kepada orang lain. }\end{array}$ & 2 & 4 & 11 & 51 & 39 & 4,13 & Baik \\
\hline 3. & $\begin{array}{l}\text { Saya mendorong teman atau relasi } \\
\text { untuk menggunakan jasa party planner } \\
\text { ORGANIZER.id. }\end{array}$ & 1 & 3 & 18 & 53 & 32 & 4,05 & Baik \\
\hline \multicolumn{7}{|c|}{ Rata - Rata Keseluruhan } & 4,11 & Baik \\
\hline
\end{tabular}

Sumber: Data diolah, 2018 
Hasil pengolahan data untuk pengujian hipotesis, berturut-turut disajikan pada Tabel 8 dan Tabel 9. Keduanya disajikan sebagai dasar menyusun persamaan struktural 1 dan 2.

Tabel 8.

Hasil Analisis Regresi Berganda Persamaan Regresi 1

\begin{tabular}{lccccc}
\hline \multirow{2}{*}{ Model } & \multicolumn{2}{c}{ Unstandardized Coefficients } & $\begin{array}{c}\text { Standardized } \\
\text { Coefficients }\end{array}$ & T & Sig. \\
\cline { 2 - 4 } & $\mathbf{B}$ & Std. Error & Beta & & \\
\hline (Constant) & 2,926 & 0,899 & & 3,255 & 0,002 \\
X1 & 0,176 & 0,057 & 0,251 & 3,098 & 0,003 \\
X2 & 0,564 & 0,082 & 0,560 & 6,922 & 0,000 \\
\hline $\mathbf{R}$ & 0,735 & & & & \\
$\mathbf{R}^{\mathbf{2}}$ & 0,534 & & & & \\
Adjusted $\mathbf{R}^{\mathbf{2}}$ & 0,525 & & & & \\
F hitung & 59,494 & & & & \\
Sig. F & 0,000 & & & &
\end{tabular}

Persamaan struktural untuk hipotesis 1 dan 2 dapat disusun sebagai berikut:

$$
\begin{aligned}
& Y_{1}=a+\beta_{1} X_{1}+\beta_{2} X_{2}+\varepsilon_{1} \ldots \ldots \ldots \ldots \ldots \ldots \\
& Y_{1}=2,926+0,176 X_{1}+0,564 X_{2}+\varepsilon_{1}
\end{aligned}
$$

Tabel 9.

\begin{tabular}{|c|c|c|c|c|c|}
\hline \multirow[t]{2}{*}{ Model } & \multicolumn{2}{|c|}{ Unstandardized Coefficients } & \multirow{2}{*}{$\begin{array}{c}\text { Standardized } \\
\text { Coefficients } \\
\text { Beta }\end{array}$} & \multirow[t]{2}{*}{$\mathbf{t}$} & \multirow[t]{2}{*}{ Sig. } \\
\hline & B & Std. Error & & & \\
\hline (Constant) & 3,778 & 1,093 & & 3,456 & 0,001 \\
\hline Y1 & 0,688 & 0,087 & 0,612 & 7,925 & 0,000 \\
\hline $\mathbf{R}$ & 0,612 & & & & \\
\hline $\mathbf{R}^{2}$ & 0,374 & & & & \\
\hline Adjusted R & 0,368 & & & & \\
\hline F hitung & 62,810 & & & & \\
\hline Sig. F & 0,000 & & & & \\
\hline
\end{tabular}

Hasil Analisis Regresi Berganda Persamaan Regresi 2

Persamaan struktural untuk hipotesis 3 dapat disusun sebagai berikut:

$$
\begin{aligned}
& Y_{2}=b+\beta_{3} Y_{1}+\varepsilon_{2} \ldots \ldots \ldots \ldots \ldots \ldots \ldots \\
& Y_{2}=3,779+0,688 Y_{1}+e_{2}
\end{aligned}
$$


Sebelum diinterpretasikan, kedua persamaan tersebut diuji melalui uji kelayakan model dan uji asumsi klasik, yang hasilnya disajikan mulai Tabel 10 sampai Tabel 15 .

Tabel 10.

Hasil Uji Normalitas Persamaan Regresi 1

\begin{tabular}{cc}
\hline & Unstandardized Residual \\
\hline $\mathrm{N}$ & 107 \\
Kolmogorov Smirnov & 1,140 \\
Asymp. Sig. (2-tailed) & 0,148 \\
\hline
\end{tabular}

Sumber: Data diolah, 2018

Tabel 11.

Hasil Uji Normalitas Persamaan Regresi 2

\begin{tabular}{cc}
\hline & Unstandardized Residual \\
\hline $\mathrm{N}$ & 107 \\
Kolmogorov Smirnov & 1,136 \\
Asymp. Sig. (2-tailed) & 0,099 \\
\hline
\end{tabular}

Sumber: Data diolah, 2018

Berdasarkan Tabel 10 dan 11, diperoleh hasil bahwa regresi persamaan 1 dan persamaan 2 memiliki nilai Asymp. Sig. sebesar 1,140 dan 1,136>0,05 yang artinya data berdistribusi normal dan model yang dibuat adalah layak digunakan untuk analisis lebih lanjut.

Tabel 12.

Hasil Uji Multikolinearitas Regresi Persamaan 1

\begin{tabular}{ccc}
\hline Model & \multicolumn{3}{c}{ Colinearity Statistic } \\
\cline { 2 - 3 } & Tolerance & VIF \\
X1 & 0,686 & 1,459 \\
& 0,686 & 1,459 \\
\hline
\end{tabular}

Sumber: Data diolah, 2018 
Tabel 13.

Hasil Uji Multikolinearitas Regresi Persamaan 2

\begin{tabular}{ccr}
\hline Model & \multicolumn{2}{c}{ Colinearity Statistic } \\
\cline { 2 - 3 } & Tolerance & VIF \\
\hline Y1 & 1,000 & 1,000 \\
\hline
\end{tabular}

Sumber: Data diolah, 2018

Tabel 12 dan 13 memiliki nilai Tolerance $>10$ persen $(0,01)$ dan seluruh nilai VIF pada model regresi tersebut memiliki nilai $<10$, artinya model regresi yang dibuat tidak terdapat gejala multikolinieritas sehingga model tersebut dapat digunakan untuk analisis lebih lanjut.

Tabel 14.

Hasil Uji Heteroskedastisitas Regresi Persamaan 1

\begin{tabular}{ccc}
\hline Model & Sig. & Keterangan \\
\hline X1 & 0,351 & Lolos Uji \\
X2 & 0,116 & Lolos Uji \\
\hline
\end{tabular}

Sumber: Data diolah, 2018

Tabel 15.

Hasil Uji Heteroskedastisitas Regresi Persamaan 2

\begin{tabular}{ccc}
\hline Model & Sig. & Keterangan \\
\hline Y1 & 0,118 & Lolos Uji \\
\hline
\end{tabular}

Sumber: Data diolah, 2018

Tabel 14 dan 15 menunjukkan bahwa tingkat signifikan dari semua variabel pada model yang digunakan tidak berpengaruh signifikan terhadap absolut residual karena tingkat signifikansi seluruh variabel bernilai diatas 5 persen $(0,05)$, maka disimpulkan model regresi yang digunakan tidak terjadi gejala heteroskedastisitas. 
Tabel 16.

\section{Hasil Uji ANOVA Regresi 1}

\begin{tabular}{clcccccc}
\hline \multirow{2}{*}{ Model } & & Sum of Squares & df & Mean Square & F & Sig. \\
\cline { 3 - 7 } & Regression & 235.895 & 2 & 117.947 & 59.494 & $.000^{\mathrm{b}}$ \\
\multirow{2}{*}{1} & Residual & 206.18 & 104 & 1.983 & & \\
& Total & 442.075 & 106 & & & \\
\hline
\end{tabular}

a. Dependent Variabel: Y1

b. Predictors: (Constant), X2, X1

Sumber: Data diolah, 2018

Nilai sig. F pada Tabel 16 yaitu $0,000<\alpha=5$ persen $(0,05)$, maka $\mathrm{H}_{0}$ ditolak dan $\mathrm{H}_{1}$ diterima artinya variabel kualitas pelayanan dan persepsi nilai secara simultan berpengaruh signifikan terhadap kepuasan pelanggan jasa party planner.

Tabel 17.

Hasil Uji ANOVA Regresi 2

\begin{tabular}{|c|c|c|c|c|c|c|}
\hline \multicolumn{7}{|c|}{$\mathrm{ANOVA}^{\mathrm{a}}$} \\
\hline Model & & Sum of Squares & df & Mean Square & $\mathrm{F}$ & Sig. \\
\hline \multirow{3}{*}{1} & Regression & 209.436 & 1 & 209.436 & 62.81 & $.000^{\mathrm{b}}$ \\
\hline & Residual & 350.115 & 105 & 3.334 & & \\
\hline & Total & 559.551 & 106 & & & \\
\hline
\end{tabular}

a. Dependent Variabel: Y2

b. Predictors: (Constant), Y1

Sumber: Data diolah, 2018

Nilai sig. F pada Tabel 17 yaitu sebesar $0,000<\alpha=5$ persen $(0,05)$, maka $\mathrm{H}_{0}$ ditolak dan $\mathrm{H}_{1}$ diterima artinya variabel kepuasan pelanggan secara simultan berpengaruh signifikan terhadap peningkatan word of mouth jasa party planner.

Berdasarkan Tabel 8 dan 9 diketahui nilai $\mathrm{R}_{1}{ }^{2}=0,534$ dan $\mathrm{R}_{2}{ }^{2}=0,374$, maka diperoleh nilai eror untuk masing-masing persamaan dengan cara sebagai berikut: 


$$
\begin{aligned}
& \mathrm{e}=\sqrt{1-\mathrm{Ri}^{2}} \\
& \mathrm{e}_{1}=\sqrt{1-\mathrm{R}^{2}}=\sqrt{1-0,534^{2}}=0,683 \\
& \mathrm{e}_{2}=\sqrt{1-\mathrm{R}_{2}{ }^{2}}=\sqrt{1-0,374^{2}}=0,791
\end{aligned}
$$

Berdasarkan perhitungan nilai standar eror, didapatkan hasil $e_{1}$ sebesar 0,683 dan $e_{2}$ sebesar 0,791 . Hasil koefisien determinasi total dihitung sebagai berikut:

$$
\begin{aligned}
\mathrm{R}^{2} \mathrm{~m} & =1-\left(\mathrm{Pe}_{1}\right)^{2}\left(\mathrm{Pe}_{2}\right)^{2} \ldots \ldots \\
\mathrm{R}^{2} \mathrm{~m} & =1-(0,683)^{2}(0,791)^{2} \\
& =1-(0,407)(0,625) \\
& =1-0,292 \\
& =0,708
\end{aligned}
$$

Nilai determinasi total sebesar 0,708 memiliki arti bahwa sebesar 70,8\% variasi variabel kepuasan pelanggan dan word of mouth dipengaruhi oleh kualitas pelayanan dan persepsi nilai, sedangkan sisanya sebesar $29,2 \%$ dijelaskan oleh faktor lain di luar model.

Nilai sig. t pada Tabel 8 sebesar 0,003 dan $0,000<0.05$ yang artinya $\mathrm{H}_{0}$ ditolak dan $\mathrm{H}_{1}$ diterima, maka kualitas pelayanan dan persepsi nilai secara parsial berpengaruh positif dan signifikan terhadap kepuasan pelanggan jasa party planner. Dalam tabel yang sama juga diperoleh koefisien variabel kualitas pelayanan $\left(\mathrm{X}_{1}\right)$ sebesar 0,176 dan koefisien variabel persepsi nilai $\left(\mathrm{X}_{2}\right)$ sebesar 0,564 yang diasumsikan jika terdapat kenaikan kualitas pelayanan dan persepsi 
nilai sebanyak 1 persen maka akan meningkatkan rata-rata kepuasan pelanggan jasa party planner sebesar 0,176 persen dengan asumsi variabel lainnya konstan.

Nilai sig. t pada Tabel 9 sebesar $0,000<0,05$ yang artinya $\mathrm{H}_{0}$ ditolak dan $\mathrm{H}_{1}$ diterima, maka kepuasan pelanggan secara parsial berpengaruh positif dan signifikan terhadap peningkatan word of mouth jasa party planner. Dalam tabel yang sama juga diperoleh koefisien variabel kepuasan pelanggan $\left(\mathrm{Y}_{1}\right)$ sebesar 0,688 yang berarti jika diasumsikan terdapat kenaikan kepuasan pelanggan sebanyak 1 persen maka akan meningkatkan rata-rata word of mouth baik jasa party planner sebesar 0,176 persen dengan asumsi variabel lainnya konstan.

Pengaruh kualitas pelayanan dan persepsi nilai terhadap kepuasan pelanggan dalam penelitian ini diperoleh nilai koefisien $\beta_{1}$ sebesar 0,176 dan $\beta_{2}$ sebesar 0,564 dengan tingkat signifikansi $0,000 \leq 0,05$ sehingga $\mathrm{H}_{1}$ diterima dan $\mathrm{H}_{0}$ ditolak, yang mengindikasikan bahwa kualitas pelayanan dan persepsi nilai berpengaruh positif dan signifikan terhadap kepuasan pelanggan.

Hasil penelitian ini sejalan dengan penelitian sebelumnya yang dilakukan oleh Nuseir et al. (2010), Khan et al. (2012), Satmoko (2016), Firdous dan Rahela (2017), Silvestri et al. (2017), Ngadino et al. (2017), Patterson dan Spreng (1997) dalam Chang et al. (2012), Wu (2014), Su (2012) dalam Chang et al. (2016), dan Hapsari et al. (2016).

Sedangkan, pengaruh antara kepuasan pelanggan terhadap word of mouth diperoleh nilai koefisien $\beta_{3}$ sebesar 0,688 dengan tingkat signifikansi $0,000 \leq 0,05$ sehingga $\mathrm{H}_{3}$ diterima dan $\mathrm{H}_{0}$ ditolak, yang mengindikasikan bahwa kepuasan pelanggan berpengaruh positif dan signifikan terhadap word of mouth. Artinya, 
semakin tinggi tingkat kepuasan pelanggan yang diberikan oleh ORGANIZER.id kepada para pelanggannya maka akan semakin mendorong terciptanya word of mouth baik tentang ORGANIZER.id. Hal ini sejalan dengan penelitian sebelumnya yang dilakukan oleh Priharmoko, (2003), Kurniawan, (2016), Prabowo dan Suryono (2016), dan Yucekaya et al. (2017).

\section{SIMPULAN DAN SARAN}

Hal-hal yang dapat disimpulkan berdasarkan pembahasan sebelumnya adalah kualitas pelayanan dan persepsi nilai berpengaruh positif dan signifikan terhadap kepuasan pelanggan artinya, semakin baik kualitas pelayanan dan persepsi nilai yang diberikan ORGANIZER.id kepada para pelanggannya maka semakin meningkat kepuasan yang dirasakan pelanggan jasa ORGANIZER.id. Kepuasan pelanggan berpengaruh positif dan signifikan terhadap word of mouth. Hasil ini berarti bahwa semakin baik kepuasan yang dirasakan pelanggan jasa party planner ORGANIZER.id maka intensitas word of mouth yang positif dari pelanggan akan semakin meningkatkan juga.

Saran yang dapat diberikan bagi perusahaan agar lebih fokus dalam meningkatkan kualitas pelayanan dari jasa party planner baik dari kesanggupan karyawan untuk merealisasikan keinginan pelanggan dan kesigapan karyawan dalam menangani permintaan serta keluhan pelanggan dan merancang strategi pemasaran baru yang lebih inovatif guna memenangkan persaingan dengan jasa party planner lainnya, serta menambah lingkup kerjasama dengan beberapa hotel, cafe, atau restoran. Perusahaan juga disarankan untuk merancang produk baru yang berkaitan dengan pesta seperti menyediakan fasilitas baru untuk mendukung 
pesta atau acara dari pelanggan yang menggunakan ORGANIZER.id, antara lain menyediakan jasa foto (photo shoot), menyediakan jasa desain (undangan, kartu ucapan, kartu nama, logo) dan lain sebagainya. Penelitian selanjutnya juga diharapkan agar mampu mengembangkan model penelitian dengan menambahkan variabel - variabel yang memiliki pengaruh terhadap word of mouth elektronik (media sosial, email, dsbnya) sehingga lebih spesifik dan didukung dengan teori teori maupun isu - isu terbaru dan mengembangkan lagi ruang lingkup dan lokasi penelitian lain sehingga mampu diimplementasikan secara umum.

\section{REFERENSI}

Augusty, Ferdinand. (2006). Metode Penelitian Manajemen. Semarang: Badan Penerbit Universitas Diponegoro.

Ahmad, Nawaz; Vveinhardt, Jolita; Ahmed, Rizwan Raheem. (2014). Impact of Word of Mouth on Consumer Buying Decision. European Journal of Business and Management. 6 (31): 394.

Chang, C. C., Wu, H. Y., Lin, H. H., \& Chang, H. Y. (2016). A Study Of Customer's Perceived Quality, Perceived Value, Expectation And Satisfaction To Its Brand Loyalty: The Case Of" Globe Trotter" Sportswear In Taiwan. Asbbs Proceedings, 23(1), 112.

Cockrill, Antje, Mark M.H. Goode. (2010). Perceived Price and Price Decay in the DVD Marke. The Journal of Product and Brand Management, 19 (5).

Cristo, M., Saerang, D. P., \& Worang, F. (2017). The Influence Of Price, Service Quality, and Physical Environment on Customer Satisfaction. Case Study Markobar Cafe Mando. Jurnal Riset Ekonomi, Manajemen, Bisnis Dan Akuntansi. 5(2).

Dye, Renee. (2000). “The Buzz on Buzz," Harvard Business Review. 78 (6). 
Firdous, Sadaf, and Rahela Farooqi. (2017). "Impact of Internet Banking Service Quality on Customer Satisfaction." The Journal of Internet Banking and Commerce. 22 (1): 1-17.

Ghozali, Imam. (2013). Aplikasi Analisis Multivariate dengan Program SPSS. Edisi Keempat, Semarang: Penerbit Universitas Diponogoro

Ghozali, Imam. (2016). Aplikasi Analisis Multivariete dengan Program IBM SPSS 21. Semarang: Badan Penerbit Universitas Diponegoro

Harjati, Lily dan Yurike Venesia. (2015). Pengaruh Kualitas Pelayanan dan Persepsi Hargaterhadap Kepuasan Pelanggan pada Maskapai Penerbangan Tiger Air Mandala, Kwik Kian Gie School of Bussines. E-Journal Widya Ekonomika. Vol 1 No.1

Hapsari, R., Clemes, M., \& Dean, D. (2016). The Mediating Role of Perceived Value on The Relationship Between Service Quality and Customer Satisfaction: Evidence from Indonesian Airline Passengers. Procedia Economics And Finance. 35 : 388-395.

Harsasi, Meirani.(2006).“Word Of Mouth dalam Industri Jasa Kaitannya dengan Sikap dan Kemungkinan Membeli”. Jurnal Bisnis Strategis. 15 (1): 31-41.

Hernawan. (2010). 10 Karakter Unik Konsumen Indonesia, Marketing.co.id, Portal Lengkap Dunia Marketing. http://www.marketing.co.id/10-karakterunik-konsumen-indonesia/. Diakses tanggal 11 Oktober 2017

https://kbbi.web.id/puas. Diakses tanggal 10 Oktober 2017

Wu, H. C. (2014). The Effects of Customer Satisfaction, Perceived Value, Corporate Image and Service Quality on Behavioral Intentions in Gaming Establishments. Asia Pacific Journal of Marketing and Logistics, 26 (4): 540-565.

Iglesias, Marta Pedraja dan M.Jesus Yagile Guillen. (2004). Perceived Quality and Price :Their Impact on the Satisfaction of Restaurant Customers. Internasional Journal of Contemporary Hospital Management, 16(6), hal.373- 379.

Kertajaya, Hermawan. (2002). Marketing Plus 2000. Jakarta: Gramedia

Khan, S., Hussain, S. M., and Yaqoob, F. (2013). Determinants of Customer Satisfaction in Fast Food Industry A Study of Fast Food Restaurants Peshawar Pakistan. Studia commercialia Bratislavensia, 6 (21), 56-65. 
Kotler dan Keller. (2012). Marketing Management Edisi 14, Global Edition, Pearson Prentice Hall.

Kotler, Philip dan Gary Armstrong. (2012). Prinsip - Prinsip Pemasaran. Edisi 12. Jilid 1. Jakarta: Erlangga.

Kurniawan, D. A. (2016). Pengaruh Persepsi Harga, Kualitas Pelayanan dan Citra Terhadap Niat Konsumen untuk Word of Mouth dengan Kepuasan sebagai Variabel Mediasi (Survei pada BPJS di Kabupaten Ponorogo). Al Tijarah. 2 (1): 94-118.

Kuo, Hui Yi. (2012). Modelling the Influence of Green Brand Image on Brand Loyalty in Technology Products: Relationships Among Green Brand Image, Brand Identification, Perceived Value and Brand Loyalty. Alliant International University, Alliant School of Management : San Diego.

Lai, Y. H. R., Chu, J. Y., \& Petrick, J. F. (2016). Examining The Relationships Between Perceived Value, Service Quality, Satisfaction, and Willingness To Revisit A Theme Park. University of Massachusetts Amherst Libraries

Lovelock, C. H. (2001). Services Marketing (4th Edition.), Upper Saddle River, N. J : Prentice Hall International.

Ngadino, Surip; Pawirosumarto Suharno; Liestijati Farida. (2017). The Effect Of Products, Price and Service Quality on Customer Satisfaction In "Rice For The Poors" Program. University of Mercu Buana: Jakarta. 12 (72): 6-18

Nuseir, M.T., Akroush, M.N., Mahadin, B.K. and Bataineh, A.Q. (2010). 'The Effect of E-Service Quality on Customers' Satisfaction in Banks Operating in Jordan: an Empirical Investigation of Customers Perspectives. Int.J.Services, Economics and Management. 2 (1): 80-108.

Manu, Very Marcus dan Dharmmesta, Basu Swastha. (2016). Analisis Persepsi Nilai Pelanggan dan Persepsi Nilai Program Terhadap Kepuasan Pelanggan dan Pengaruhnya pada Loyalitas Pelanggan dan Niat Pembelian Kembali: Studi Frequent Flyer Program Garuda Mile. Phd Thesis. Universitas Gadjah Mada.

Moraga, Eduardo, Arturo Z. Vasques Parraga dan JorgeZamora Gonzales. (2008). Customer Satisfaction and Loyalty: Start With The Product, Culmite With The Brand. Journal of Consumer Marketing, 25(5), pp. 302-313.

Mulyana. (2002).’Kepuasan Pelanggan Sebagai Keunggulan Daya Saing”. Jurnal Ekonomi dan Bisnis. 3 (2) hal.95-103. 
Muhammad Basalamah, Fauzan. (2010). Pengaruh Komunitas Merek terhadap Word of Mouth, Bisnis \& Birokrasi. Jurnal Ilmu Administrasi dan Organisasi. hal. 79-89

Peter, J. Paul and Jerry C. Olson. (2000). Consumer Behavior: Perilaku Konsumen dan Strategi Pemasaran. Cetakan Pertama Edisi Bahasa Indonesia. Penerbit Erlangga. Jakarta.

Prabowo, Adi Dan Suryono Budi Santoso. (2016). Analisis Pengaruh Kualitas Pelayanan Inti dan Kualitas Pelayanan Periferal Terhadap Word of Mouth Melalui Kepuasan Pelanggan Catering Ida, Semarang. Diponegoro Journal of Management. 5 (3).

Praswati, Aflit Nuryulia. (2009). Analisis Faktor-faktor yang Mempengaruhi Komunikasi Word Of Mouth terhadap Minat Guna Jasa Ulang (Studi pada PT Nasmoco di Semarang). Magister Manajemen Universitas Diponegoro.

Priharmoko, Patria. (2003). Faktor-Faktor yang Mempengaruhi Perilaku Word Of Mouth Konsumen (Studi pada Pelanggan Kartu Halo Telkomsel). Universitas Indonesia.

Primantara, Windu. (2017). Peran Kepuasan Memediasi Kualitas Pelayanan Terhadap WOM Pada RSU Surya Husadha Denpasar. E-Jurnal Manajemen pada Fakultas Ekonomi dan Bisnis Universitas Udayana, Vol.6 No.7.

Putra, Fahrainsyah Wahyu dan Eka Sulistyawati. (2017). Peran Kepuasan Pelanggan Dalam Memediasi Pengaruh Kualitas Pelayanan Terhadap Loyalitas Pelanggan (Studi Pada Rumah Makan Bakmi Tungku Di Kabupaten Badung). E-Jurnal Manajemen Universitas Udayana, 7 (1), hal. $525-554$.

Putra, Susanto Doni, Seno S., dan Anwar A. (2017). Pengaruh Kualitas Produk, Kualitas Pelayanan, dan Harga Terhadap Kepuasan Pelanggan (Studi Pada Usaha Rumahan Kerupuk Ikan Super Besuki Situbondo). Jurnal Manajemen Bisnis Indonesia, 3(1).

Raharjo, C. A., Amboningtyas, D. (2017). The Effect of Service Quality, Price and Brand Image on Consumer Loyalty with Customer Satisfaction as Moderating on The Point" Barokah" Sikopek. Journal of Management, 3(3).

Rahyuda, Ketut. (2016). Metode Penelitian Bisnis. Denpasar: Udayana University Press 
Saputra, Angga dan Suryono Budi Santoso. (2011). Analisis Pengaruh Kepuasan, Kualitas, Dan Experiential Marketing Terhadap Word Of Mouth Situs Jejaring Sosial Facebook Pada Mahasiswa FE Undip Semarang. Undergraduate thesis, Universitas Diponegoro.

Satmoko, Taufiq Dwi. (2016). Pengaruh Kualitas Pelayanan Terhadap Word Of Mouth, Melalui Kepercayaan dan Kepuasan Konsumen Sebagai Variabel Intervening Pada Star Clean Car Wash Semarang. E Journal UNDIP.

Shao, Chang Li. (2013). Exploring The Relationships among Service Quality, Customer Loyalty and Word of Mouth for Private Higher Education in Taiwan. Asia Pasific Management Review, 18(4) : 375 - 389.

Silvestri, Cecilia, Barbara Aquilani, Alessandro Ruggieri. (2017). "Service Quality and Customer Satisfaction in Thermal Tourism". The TQM Journal. 29 (1): 55-81.

Simamora, Henry. (2001). Manajemen Sumber Daya Manusia. STIE YKPN : Yogyakarta.

Sinaga, Eka Mayastika. (2011). Menciptakan Word Of Mouth Melalui Kualitas Pelayanan. Jurnal Manajemen 2011, 4(5) : 1-11

Sugiyono. (2012). Metode Penelitian Kuantitatif Kualitatif dan R\&D. Bandung: Alfabeta.

Sugiyono. (2014). Metode Penelitian Bisnis. Bandung: Alfabeta

Surbakti. (2013). Analisis Pengaruh Kepemimpinan Transformasional dan Motivasi terhadap Kinerja Karyawan: Studi pada PT. Kereta Api Indonesia Daop IV Semarang. Jurnal Fakultas Ekonomi Universitas Diponegoro Semarang, 1 (1), hal. 55-67

Susie, Khoo, Huong Ha, Sue L.T. McGregor. (2017). "Service Quality and Student/Customer Satisfaction in The Private Tertiary Education Sector in Singapore", International Journal of Educational Management. 31 (4):430444.

Tangkilisan, Hessel Nogi S. (2005). Manajemen Publik, Jakarta: PT. Gramedia Widiasarana

Tjiptono, Fandy \& Chandra. (2011). Service, Quality \& Satisfaction. Penerbit Andi: Yogyakarta.

Umar, Husein. (2003). Metode Riset Perilaku Konsumen Jasa. Ghalia Indonesia: Jakarta. 
Utama, Made Suyana. (2014). Aplikasi Analisis Kuantitatif. Edisi Kedelapan. Denpasar.

Widyaswati, Rahmatya. (2010). Analisis Faktor - Faktor yang Mempengaruhi Kepuasan sehingga Tercipta Word of Mouth yang Positif pada Pelanggan Speedy di Semarang. Masters Thesis, Universitas Diponegoro.

Wirawan, Nata. (2012). Cara Mudah Memahami Statistik 1 (Statistik Deskriptif), Edisi 1. Denpasar: Keramat Emas. Hal:35.

Yucekaya, Polat; Rencber, Omer Faruk; Canoglu, Meltem. (2017). The Effect Of Store Image And Word of Mouth Marketing On Customer Satisfaction: A Research In Çanakkale Province. Journal Management, Markerting And Logistics. 4 (4) : 438-447. 